\title{
Professoras idosas do campo: narrativas sobre formação e prática pedagógica
}

\author{
Elderly teachers from the countryside: narratives \\ about formation and pedagogical practice
}

Maestras mayores del campo: narraciones sobre

formación y práctica pedagógica

MARIA ANTÔNIA SOUZA (iDa

Maria de Fátima Rodrigues Pereira (idb)

Maria Iolanda Fontana (D)

\section{Resumo}

Este artigo traz resultados da pesquisa sobre professoras idosas que vivem no campo, em duas regiões do estado do Paraná. O objetivo é compreender a prática pedagógica, a formação inicial e continuada que as professoras tiveram ao longo da trajetória profissional. Os sujeitos da pesquisa são 20 professoras que possuem acima de 60 anos, são moradoras do campo e sempre trabalharam em escolas rurais. A partir de entrevistas semiestruturadas com 7 professoras moradoras do campo e relatos orais de 13 professoras que sempre trabalharam em escolas rurais, é possível afirmar que a prática pedagógica está assentada em quatro aspectos, a saber: formação generalista, independente do contexto agrário brasileiro; organização curricular e conteúdos direcionados à instrução dos alunos; planejamento centrado na decisão das professoras e supervisão realizada pelas secretarias municipais e estadual de educação e proximidade da escola e das professoras com as comunidades, possibilitando articulação entre as atividades realizadas pelas famílias na agricultura e os conteúdos escolares. As professoras se formaram no e pelo trabalho pedagógico. A própria experiência e o apoio de outras professoras propiciavam o aprendizado da docência. Por meio do projeto Logos, a maioria teve acesso à formação pedagógica inicial. Elas

a Universidade Estadual de Ponta Grossa (UEPG), Ponta Grossa, PR, Brasil. Doutora em Educação, e-mail: masouza@uol.com.br

b Universidade Tuiuti do Paraná (UTP), Curitiba, PR, Brasil. Doutora em Filosofia e História da Educação, e-mail: maria.pereira@utp.br

c Universidade Tuiuti do Paraná (UTP), Curitiba, PR, Brasil. Doutora em Educação, e-mail: maria.fontana1@utp.br 
demonstram estreita relação entre a vida pessoal-familiar e o trabalho na escola. Cada criança é como se fosse um filho, o que revela perspectivas solidárias e de sociabilidade com as famílias. As professoras sentem-se realizadas no trabalho efetivado ao longo da vida e demonstram saudades do tempo difícil da docência em escola isolada e multisseriada.

Palavras-chave: Professoras Idosas. Narrativas. Prática Pedagógica. Formação de Professores. Educação Rural.

\begin{abstract}
This article presents results of the research on elderly teachers who live in the countryside, in two regions of Paraná state. The objective is to understand the pedagogical practice, the initial and continuing formation that teachers had throughout their professional trajectory. The research subjects are 20 teachers who are over 60 years old, live in the countryside and have always worked in rural schools. From semistructured interviews with 7 teachers living in the countryside and oral reports from 13 teachers who have always worked in rural schools, it is possible to state that the pedagogical practice is based on four aspects: generalist formation, regardless of the Brazilian agrarian context; curricular organization and content directed to the students' instruction; planning centered on the teachers' decision and supervision carried out by the municipal and state departments of education and proximity of the school and the teachers to the communities, enabling articulation between the activities carried out by the families in agriculture and school content. Teachers were formed in and through pedagogical work. The own experience and the support of other teachers provided teaching learning. Through the Logos project, most of them had access to initial pedagogical formation. They demonstrate a close relationship between personal-family life and school work. Each child is like a child, revealing perspectives of solidarity and sociability with families. The teachers feel fulfilled in their work throughout their lives and show they miss their difficult time of teaching in an isolated and multiple-grades school.
\end{abstract}

Keywords: Elderly teachers. Narratives. Pedagogical Practice. Teacher formation. Rural Education.

\title{
Resumen
}

Este artículo presenta los resultados de la investigación sobre maestros de edad avanzada que viven en el campo, en dos regiones del estado de Paraná. El objetivo es comprender la práctica pedagógica, la formación inicial y continua que los docentes tuvieron a lo largo de su trayectoria profesional. Los sujetos de investigación son 20 maestras que tienen más de 60 años, viven en el campo y siempre han trabajado en escuelas rurales. A partir de entrevistas semiestructuradas con 7 docentes que viven en el campo e informes orales de 13 docentes que siempre han trabajado en escuelas rurales, es posible afirmar que la práctica pedagógica se basa en cuatro aspectos: formación generalista, independientemente del contexto agrario brasileño, organización curricular y contenido dirigido a la instrucción de los estudiantes, planificación centrada en la decisión de los maestros y supervisión realizada por los 
departamentos de educación y proximidad de la escuela y los maestros a las comunidades. Las docentes se formaron en y a través del trabajo pedagógico. La propia experiencia y el apoyo de otros docentes proporcionaron enseñanza aprendizaje. A través del proyecto Logos, la mayoría de ellas tuvo acceso a la formación pedagógica inicial. Demuestran una estrecha relación entre la vida personal y familiar $y$ el trabajo escolar. Cada estudiante es como un niño, revelando perspectivas de solidaridad y sociabilidad con las familias. Las maestras se sienten satisfechas en su trabajo a lo largo de sus vidas y muestran que extrañan su difícil momento de enseñar en una escuela aislada y de varios grados.

Palabras clave: Maestras mayores. Narrativas. Práctica pedagógica. Formación docente. Educación rural.

\section{Introdução}

Este artigo tem o objetivo de problematizar as narrativas das professoras idosas sobre a escola rural, a formação e a prática pedagógica. É fruto de pesquisa desenvolvida em duas regiões do estado do Paraná - Região Metropolitana de Curitiba (RMC) e a Região dos Campos Gerais, com professoras idosas que vivem no campo e na cidade e que construíram a trajetória profissional nas escolas rurais municipais.

Foram realizadas entrevistas de natureza narrativa com sete professoras e coletados relatos orais em espaço coletivo com outras 13. As professoras idosas foram identificadas mediante contato com o Núcleo de Pesquisa em Educação do Campo, Movimentos Sociais e Práticas Pedagógicas (NUPECAMP), localizado na Região Metropolitana de Curitiba, e com pedagogas atuantes nos municípios dos Campos Gerais. Após a identificação das primeiras entrevistadas, as outras vieram pelo critério bola de neve.

As duas regiões escolhidas para a pesquisa têm em sua composição municípios marcadamente rurais. A RMC possui 29 municípios, de acordo com a classificação da COMEC (Coordenação da Região Metropolitana de Curitiba). Dentre eles há 18 municípios com fortes marcas rurais, como o trabalho com a agricultura, amplas áreas de proteção ambiental e baixa densidade demográfica. A Região dos Campos Gerais é composta por 19 municípios, pelos critérios da AMCG (Associação dos Municípios dos Campos Gerais), sendo 18 deles marcadamente 
rurais, e quatro estão entre os 10 maiores em extensão territorial no estado do Paraná.

O Brasil é um país que possui densidade demográfica de 22,5 hab $/ \mathrm{km}^{2}$, ou seja, marcadamente rural. De acordo com o Censo Escolar do INEP (2018), das 181.939 escolas da Educação Básica, 124.330 estão no espaço urbano e 57.609 estão no espaço rural. Cerca de $21 \%$ do total de escolas é de pequeno porte, ou seja, possui até 50 matrículas. A grande maioria delas está localizada no campo. No país, o total de docentes trabalhando nos anos iniciais é de 762.884, sendo 4,3\% possuidores de escolaridade condizente com o ensino médio ou inferior; $11 \%$ possui o médio normal ou magistério; $6 \%$ possui o ensino superior em andamento; $1,2 \%$ possui o ensino superior completo/bacharelado e $77,3 \%$ possui o superior completo/licenciatura. A maior parte dos que possuem escolaridade condizente ou inferior ao ensino médio trabalha em escolas localizadas no campo.

Esses dados são de 2018 e revelam os problemas que persistem na sociedade brasileira. Por exemplo, em 2002, conforme publicação do INEP (2006), 8,3\% dos docentes que atuavam no ensino fundamental, na área rural, tinham até o ensino fundamental concluído, ao passo que na área urbana, nessa categoria, o total era de 0,8\%. Possuindo ensino médio completo eram 82,90\% na área rural e 61,10\% na urbana. Com o ensino superior concluído eram 8,80\% no rural e 38,10\% na área urbana. Ainda, de acordo com o INEP (2006), em 1980, a média de anos de estudo da população brasileira era de 7 anos entre os moradores da área urbana e 3,4 anos de estudos entre os moradores da área rural. A política de fechamento de escolas no campo dificulta o acesso e, especialmente, a permanência e continuidade dos jovens nos estudos escolares. Ou seja, as escolas rurais ainda são secundarizadas na política nacional e nas locais.

As narrativas das professoras idosas demonstram que elas ingressaram no trabalho no magistério, no início dos anos de 1980, como professoras que se formaram no trabalho e na relação com professoras com maior tempo de experiência nas escolas. Nas narrativas, elas tratam de uma vida na escola e no campo marcada pelo trabalho.

Das sete professoras, duas moram sozinhas no campo, quatro vivem com os maridos e uma mora com a família do filho. As 13 professoras que fizeram relato 
coletivo de experiência vivem em cidades, com familiares. Gusmão e Alcântara (2008, p. 176) salientam que os aposentados do campo aparecem como uma nova categoria que agrega importantes recursos para as comunidades e municípios. Essa categoria mantém, muitas vezes, a pequena propriedade mesmo em meio aos processos de migração dos jovens em direção às cidades.

Assim como a maioria dos trabalhadores do campo, a trajetória das professoras é de luta cotidiana, em casa, na roça e na escola. A vida na escola é traçada pela identificação pessoal com a formação das crianças e pelo trabalho como extensão da casa e da lavoura. Relatos indicam que na escola as professoras limpavam, cozinhavam, cuidavam das crianças e ensinavam as primeiras letras. Lida-se com o espaço escolar como continuidade das relações familiares e criação de novos laços de parentesco.

Salientam-se as características do campo brasileiro, com comunidades distantes dos centros urbanos, nas quais as professoras eram elos entre famílias e escola. Eram as lideranças do processo formativo escolar, sob determinações locais e nacionais expressas nos processos avaliativos que vivenciavam. Não se pode negar que as professoras criavam experiências pedagógicas importantes com as crianças.

Cabral et al. (2010), em investigação sobre as condições de ambiente e saúde em idosos da área rural e urbana em localidade no Nordeste, encontraram que o envelhecimento da população da área rural é marcado por isolamento, haja vista que os jovens tendem a migrar para os centros urbanos em busca de trabalho e estudo; pobreza; baixa escolaridade; dificuldades com relação a transporte, problemas de saúde e moradias precárias. Dentre as dificuldades mencionadas pelos autores, é possível destacar que os fatores isolamento e acesso precário à saúde, transporte, educação e segurança são dois fatores marcantes na realidade da população idosa do campo, no Brasil. Entretanto, as narrativas das professoras não demonstram solidão e isolamento - expressam no rosto e no discurso a realização pessoal com o trabalho na escola, em meio à dureza da vida na roça.

O vínculo entre vida e trabalho é indissociável. Os sinais do tempo e do trabalho são visíveis nas expressões corporais de trabalhadoras(es) idosas(os) do campo. Da mesma forma, a resistência é a marca de uma vida inteira de luta. 
Do ponto de vista metodológico, o trabalho fundamenta-se em estudos de Queiroz (1988) sobre os relatos orais, para quem o pesquisador é aquele que está no comando do processo, provocando a fala, apresentando interrogações àquele que narra. Da mesma forma, as entrevistas supõem uma "conversação continuada entre o informante e o pesquisador", segundo a autora. Assim foi a conduta com as professoras, provocando-as com os temas vinculados ao campo, escola, prática pedagógica, formação, política educacional, material didático, relação com as comunidades etc., exercitando, especialmente, o diálogo com elas. Assim, foram construídas as entrevistas narrativas, em aproximação com as ideias de Souza (2014, p. 43), para quem:

Narrativas (auto)biográficas, construídas e/ou coletadas em processo de pesquisa ou em práticas de formação, centram-se nas trajetórias, percursos e experiências dos sujeitos, são marcadas por aspectos históricos e subjetivo frente às reflexões e análises construídas por cada um sobre o ato de lembrar, narrar e escrever sobre si.

As entrevistas narrativas foram feitas individualmente, nas casas das professoras. Os relatos orais foram coletados em um encontro organizado pelas professoras aposentadas, no final do ano de 2019. Nos relatos elas lembravam das experiências, das ajudas que umas davam às outras no início da carreira, das crianças, dos trabalhos escolares. Enfim, foi um momento de expressão da memória coletiva sobre o trabalho na escola rural e de mostrar de forma orgulhosa os trabalhos que faziam com as crianças, as cartas que recebiam delas. Neste artigo, a opção foi pela análise das narrativas de sete professoras que trabalharam e vivem no campo, considerando as contribuições aos debates sobre formação e prática pedagógica.

Em outros estados, como a Bahia, há grupos de pesquisas que trabalham narrativas de docentes de escolas rurais. Exemplo é o estudo de Coelho (2010) que analisou narrativas de professoras da Educação Infantil no meio rural. Ainda, do mesmo estado, considera-se relevante a produção de Bastos e Souza (2017) que trata da história de vida-formação de uma professora aposentada. Esses estudos auxiliaram no aprofundamento dos aspectos teóricos e metodológicos da pesquisa, por constituírem exemplares raros de investigações sobre pessoas idosas do campo.

Este artigo está organizado em três partes, a saber: a primeira traz reflexão sobre as escolas públicas rurais, a segunda trata da formação das professoras, com 
ênfase no projeto Logos, a terceira expõe aspectos do planejamento de ensino e organização curricular, bem como da relação escola-comunidade.

\section{Escolas públicas rurais: contradição e resistência}

Nesta segunda década do século XXI, a escola localizada no campo tem sido denominada de escola rural e de escola do campo. Vincula-se a escola rural à concepção de Educação Rural e a escola do campo como aquela cuja identidade é construída na prática do movimento social, à concepção de Educação do Campo. Neste artigo, as narrativas das professoras remetem o pensamento à escola rural, pois tratam do período de 1980 e 1990, quando a concepção de Educação do Campo não estava presente na sociedade brasileira. Somente ao final de 1990, por força dos movimentos sociais do campo é que se constitui a Educação do Campo. De lá em diante, a concepção de Educação Rural e a de Educação do Campo estão presentes na sociedade brasileira, a primeira vinculada diretamente às decisões governamentais e a segunda fundada pela resistência e construção coletiva de pautas importantes para as políticas públicas educacionais. Sobre o assunto, Souza (2016a) caracteriza a Educação do Campo no Brasil, fazendo contraponto com a Educação Rural.

Para compreender as narrativas das professoras, é feita contextualização da educação rural e de práticas escolares, nos currículos e na formação de professores, com recorte a partir de 1930. As políticas educacionais para as escolas públicas localizadas em áreas rurais, iniciadas na década de 1930, tiveram como propósito a conformação do indivíduo ao meio rural para formação de hábitos de trabalho, tornando-o produtivo em seu meio. A finalidade foi de evitar a migração campo-cidade, a desordem social e o empobrecimento da nação, haja vista que se compreendia o povo do campo como atrasado e como entrave ao desenvolvimento econômico e social. O ideário da escola rural buscou "agir sobre a criança, o jovem, o adulto, integrando-os todos na obra de construção da unidade nacional, para a tranquilidade, segurança e bem estar do povo brasileiro” (CALAZANS, 1993, p. 26).

Desde então, contraditoriamente aos anseios emancipatórios da população campesina, as políticas reforçaram a adequação do projeto educativo das escolas 
rurais ao modelo capitalista de produção. Isso significou a valorização da modernidade congregada nos valores da cultura urbana e a necessidade de formação de mão de obra adaptada ao desenvolvimento industrial, ao agronegócio e para as demandas da tecnificação do trabalho. A consolidação do sistema capitalista exaltou a urbanização e depreciou outras formas de relações sociais, sobretudo referentes à cultura e ao modo de produzir no meio rural, como exemplo, a agricultura familiar.

O Decreto-Lei sob $\mathrm{n}^{\circ}$ 8.529, de 2 de janeiro de 1946, conhecido como Lei Orgânica do Ensino Primário, em seu artigo 28 dispõe sobre os quatro tipos de estabelecimentos, a saber: 1) escola isolada, composta por uma turma e um docente; 2) escolas reunidas, com duas a quatro turmas e igual número de docentes; 3) grupo escolar, com cinco ou mais turmas e igual número de docentes; 4) escola supletiva, com oferta de ensino supletivo. No campo, predominavam as escolas unidocentes e turmas multisseriadas.

Situa-se o golpe militar de 1964 como marco para o impulso ao projeto de "modernização da agricultura" no Brasil, em contraposição às propostas de Reforma Agrária e ao modo de produzir no campo, engendrada, nos anos 1950 e 1960, por movimentos populares. Este processo foi alavancado pela adesão entre o capital agroindustrial com a grande propriedade fundiária, financiada pelo Estado ${ }^{1}$. Portanto, a "política adotada para a educação rural justificava-se, então, como resposta à necessidade de integrar aquelas populações ao progresso que poderia advir desse desenvolvimento" (RIBEIRO, 2012, p. 298). Como esclarece a autora, nesse contexto, intensificaram-se políticas para consolidação do modelo econômico urbano-industrial, como ocorreu na educação com a implantação da Lei $n^{\circ}$ $5.692 / 1971$ para o ensino de $1^{\circ}$ e $2^{\circ}$ graus, ao estabelecer a obrigatoriedade e adaptação da profissionalização de mão de obra para o mercado de trabalho, no meio rural e na cidade.

\footnotetext{
${ }^{1}$ Embora ações modernizantes isoladas já se evidenciassem desde os anos 1950 na agricultura brasileira, só é possível falar de um processo de modernização após o Golpe de 1964, que se contrapõe ao movimento da esquerda brasileira pela Reforma Agrária. Assim, a modernização da agricultura brasileira foi impulsionada pelo Estado, por meio da produção de máquinas e insumos para a agricultura, um sistema de pesquisa e extensão voltado para impulsionar 0 processo de modernização e de seu financiamento (ALENTEJANO, 2012, p. 480).
} 
A Lei $\mathrm{n}^{\circ}$ 5.692/1971 é omissa em reconhecer a atividade de agricultura familiar e da pequena propriedade rural, trata apenas da empresa rural. A única referência encontrada em relação ao rural refere-se à organização do calendário escolar em função da época de plantio e da colheita de safras, com o objetivo de favorecer a presença de mão de obra escolarizada no período de produção. Significa que "a importância não recai sobre a cultura, a identidade do homem rural, sua forma de relacionar-se com a natureza e com outros homens, mas sobre o lucro e sobre a renda da terra” (GRITTI, 2003, p. 39).

A crise do modelo centrado essencialmente na industrialização, financiado pelo Estado e pelo capital estrangeiro, estagnou a economia e acentuou problemas sociais no país e o empobrecimento dos povos do campo. $\mathrm{Na}$ perspectiva da nova ordem mundial e da configuração da economia globalizada, a lógica passa a ser o desenvolvimento centrado no mercado para investimentos lucrativos, custeados pela sociedade e Estado, em detrimento do desenvolvimento dos povos e de suas potencialidades.

A partir da década de 1970, a política de consolidação de escolas ou nucleação começa ser experienciada. No estado do Paraná, a primeira escola nucleada data de 1978, localizada na RMC, no município de Campo Largo, e reúne alunos que pertenciam a escolas isoladas. Assim, fecham-se escolas isoladas multisseriadas e estrutura-se uma escola maior, pautada no ensino seriado.

Nos anos de 1990, a LDBEN 9.394/96, conforme análise de Gritti (2003, p. 47), desloca, sem nenhuma mudança essencial, as orientações da escola da zona urbana para zona rural, prevendo apenas uma adaptação dos conteúdos e metodologias e de organização do calendário escolar, mas sem o reconhecimento às especificidades do trabalho e da cultura rural.

O processo de democratização da sociedade brasileira possibilitou a organização e fortalecimento da luta por educação, no contexto do Movimento dos Trabalhadores Rurais Sem Terra (MST), para reivindicar a participação de coletivos na definição de políticas públicas para os povos campesinos. Apesar de embates com segmentos do Estado, conquistaram, a partir da década de 1990, políticas dialogadas com a classe trabalhadora do campo, tais como: Programa Nacional de Educação na Reforma Agrária (Pronera), Residência Agrária, Procampo, 
Pronacampo, Programa Escola da Terra, Programa Jovem Rural entre outros. Fundamental foi a aprovação das Diretrizes Operacionais para a educação básica das escolas do campo (BRASIL, 2002), as Diretrizes Complementares (BRASIL, 2008) e o Decreto de 2010 sobre a política nacional de Educação do Campo e o Pronera (BRASIL, 2010).

O Plano Nacional de Educação (BRASIL, 2001) não tinha lugar para a Educação do Campo, ao passo que o PNE (BRASIL, 2014) registrou em todas as estratégias a Educação do Campo, por força das lutas empreendidas na década anterior pelos movimentos sociais do campo.

No entanto, os últimos anos (2015 a 2020) têm indicado retrocessos em relação às políticas da Educação do Campo, que refletem as disputas antagônicas entre os interesses dos movimentos sociais e das elites dominantes articuladas ao Estado neoliberal. Embora sejam mantidos escassos recursos financeiros e materiais para as escolas do campo, fecham-se escolas isoladas, restringe-se a oferta da licenciatura em Educação do Campo, bem como de projetos de formação continuada. Além disso, é importante registrar a extinção, em janeiro de 2019, da Secretaria de Educação Continuada, Alfabetização, Diversidade e Inclusão (SECADI) e da Coordenação de Educação do Campo.

Em síntese, as características da escola rural foram interrogadas pelos movimentos sociais do campo e fizeram emergir a identidade da escola do campo. $\mathrm{Na}$ sociedade brasileira, há predomínio de políticas educacionais voltadas para a escola rural. Porém, há experiências expressivas de escolas construídas em estreita relação com os movimentos sociais, com gestão participativa e conteúdos escolares que valorizam o trabalho e a cultura dos povos do campo, bem como suas lutas históricas pela permanência na terra.

As professoras idosas relatam a política e prática pedagógica de um tempo em que a educação rural era projetada como um dos meios para superação do atraso da população do campo, sem visibilidade das lutas da população, da reivindicação pela reforma agrária e com expressiva exposição da precariedade da escola rural como justificativa para o seu fechamento.

Adiante serão expostas narrativas das professoras, com ênfase no seu ingresso na escola rural e no processo de formação inicial. 


\section{Prática e formação: o projeto LOGOS II}

As professoras iniciaram o trabalho nas escolas rurais no ano de 1980, sob vigência da LDB 4.024/1961. Trabalharam em escolas unidocentes e multisseriadas, e vivenciaram as experiências de nucleação ou consolidação de escolas rurais, que se iniciou na década de 1970 no Brasil que teve avanços como política educacional nos anos de 1980 e 1990, especialmente. Elas eram professoras cujas experiências foram construídas no diálogo com colegas de escola, ou nos processos de formação propiciados pelo governo federal em parceria com governos estaduais e municipais, a exemplo do Projeto Logos². Outras vivenciaram processos formativos a distância, licenciaturas ofertadas pela Educação a Distância. Eram as professoras "leigas" que possuíam a sabedoria do campo, do trabalho com a terra, o conhecimento cotidiano construído na relação com as famílias dos alunos.

Dentre as sete professoras colaboradoras de pesquisa, apenas uma participou de processo formativo continuado em Educação do Campo, vinculado a pesquisas financiadas pela CAPES/Observatório da Educação. Portanto, as narrativas trataram, principalmente, da Educação Rural e das escolas rurais, de acordo com as políticas e práticas vivenciadas. Quando elas se aposentaram, nos anos de 2000 a 2010, os debates sobre Educação do Campo começavam a atingir os municípios que não possuem vínculos orgânicos com movimentos sociais do campo.

Se pouco tempo tiveram para conhecer o Movimento Nacional da Educação do Campo, seus debates, propósitos e práticas, em virtude da aposentadoria, no início do trabalho como professoras, seus estudos escolarizados não passavam de alguns rudimentos realizados em condições muito precárias.

A referência às professoras será feita pela letra $\mathrm{P}$ (professora), com a indicação dos números 1 ao 7, e pelas iniciais do município, onde trabalharam, por exemplo, professora de Campo Magro será PCP1, Tijucas do Sul será PTJ1, Piraí do

\footnotetext{
2 O projeto conhecido como Logos I e II foi criado no contexto da Lei no 5.692/1971, para dar conta do disposto no artigo 30 sobre a formação de professores. Muitos professores não possuíam formação específica para o trabalho docente, eram conhecidos como leigos. $\mathrm{Na}$ área rural, a grande maioria de professores estava na condição de leigo. 0 governo federal criou 0 projeto Logos I para oferecer formação em nível de $1^{\circ}$ grau aos professores e, num segundo momento, o projeto Logos II para propiciar a formação em nível de $2^{\circ} \mathrm{grau}$, no curso de Magistério.
} 
Sul será PPS1. A transcrição das falas preserva a pronúncia e oralidade das professoras.

Efetivamente, quando as entrevistadas foram questionadas sobre a formação com que iniciaram seu trabalho de professoras, disseram dos seus poucos anos de escolaridade e suas dificuldades: "Quando eu comecei a estudar, tinha 4 turmas. Eu era ruim de cabeça. Fiquei 8 anos na 4 série. [...], só consegui sair da $4^{\mathrm{a}}$ série em 1970” (PCM1).

Após 10 anos de trabalho na roça, a entrevistada, em 1980, foi chamada para ser professora, "Pense a minha responsabilidade! Eu já estava com 25 anos nas costas. Peguei a minha professora, que foi minha professora antes. Teve uma encrenca aqui. Ela saiu e o lugar ficou 2 anos sem professora. Eu assumi a turma dela com 48 alunos. Primeira, segunda, terceira e quarta". (PCM1).

O que aconteceu? Peguei $1^{a}, 2^{a}, 3^{a}$ e $4^{a}$, tudo numa sala só. Doei a minha casa para que fizessem essa sala de aula e fui morar num rancho de capim, porque não tinha outro lugar. Morei num ranchinho de capim. Tinha a minha escola que era um pouquinho melhor, tinha assoalho. Doei e fizemos a sala de aula, para agrupar aqueles alunos ali. $\mathrm{E}$, ali eu fiquei com os alunos 5 anos. Daí eles fizeram grupo na frente aqui. Eu morava do outro lado. Hoje o grupo tá aqui na minha frente. O telhado caiu. Voltei para cá, nesse grupo aqui em frente e fiquei 5 anos. Daí, eu era professora. (PCM1).

A condição de PCM1 de assumir escola multisseriada foi a de muitas professoras, apenas com a quarta série do nível primário, mas no seu caso sua disponibilidade foi longe, cedeu sua casa e foi morar atrás dela em um ranchinho coberto de capim. Era década de 1980, faz somente 40 anos. Mais tarde, a professora e sua comadre, ambas professoras do mesmo lugar, fizeram o projeto Logos "Nós fizemos o Logos juntas" (PCM2), "Fizemos junto" (PCM1), como que indicando o apoio que uma dava à outra. Interrogadas sobre o que era o Logos, PCM1 foi precisa: "O magistério a distância". "Eu comecei a trabalhar em fevereiro (1980), quando foi em setembro eles me chamaram para fazer o primeiro teste do Logos" (PCM1).

No final da década de 1970, início da de 1980, no contexto da implantação da Lei $n^{\circ}$ 5. 692/1971, a formação de professores tornou-se urgente. A Lei no 5.692 que reformou a primeira Lei de Diretrizes e Bases da Educação Nacional, de $n^{\circ}$ 4.024/1961, alterou a nomenclatura de ensino primário, ginasial e colegial para 
ensino de primeiro e segundo grau, fundiu o ensino primário com o ginásio, criou assim, o primeiro grau de ensino, com duração de oito anos, com obrigatoriedade para crianças e jovens na faixa etária de 7 aos 14 anos. O segundo grau, também antigo secundário, ginasial e ou colegial, foi composto de três ou quatro anos tornado compulsoriamente profissional. Se o antigo secundário e ou colegial tinha por finalidade a preparação para os estudos superiores, a Lei $\mathrm{n}^{\circ} 5.692$ configurou o segundo grau à habilitação profissional de técnicos para o comércio, agricultura, serviços. Esta reforma atingiu a formação de professores para os primeiros anos de escolaridade quando a remeteu a uma habilitação profissionalizante no ensino médio - o Magistério de nível médio. A Lei $n^{\circ}$ 5.692, inicialmente, ganhou apoio de educadores. Todavia, no contexto da abertura do regime militar civil, já na década de 1980, foi submetida ao rigor da pesquisa crítica e debate político que lhe apontou os interesses de classe, seu caráter tecnicista, e a finalidade de conter o acesso ao ensino superior por parte das classes médias e populares.

A obrigatoriedade de oito anos de escolaridade, dos 7 aos 14 anos, consagrada pela Lei no 5.692/1971 implicou demanda pela formação de professores. A situação era dramática, sobretudo, para as escolas situadas no campo. Neste contexto, vários projetos de formação de professores foram desenvolvidos nos estados. Em caráter de urgência foi criado pelo MEC o Projeto Logos I, seguido pelo Projeto Logos II que as professoras apontaram em suas entrevistas.

O Projeto Logos I foi piloto, experimental, para o qual foram selecionadas(os) 2 mil docentes leigas(os) dos estados do Piauí e Paraíba e dos territórios do Amapá, Roraima e Rondônia onde havia um grande número de professoras(es) leigos atuando em sala de aula (LIMA, 2019, p. 89). O curso tinha um total de 3.045 horas divididas por oito disciplinas: Informação, Estudos Sociais, Comunicação e Expressão, Ciências, Orientação, Educação Artística, Matemática, Técnicas Didáticas, cada uma organizada em módulos que correspondiam a uma carga horária. As disciplinas com mais módulos eram Comunicação e Expressão, em número de 10 módulos e 700 horas, seguida por Estudos Sociais com 9 módulos e 610 horas, Ciências com 8 módulos e 480 horas; Matemática vinha em quinto lugar, com 6 módulos e 530 horas (LIMA, 2019, p. 90). Não havia uma correspondência linear entre módulo e horas como se pode observar comparando Matemática e 
Ciências. Todavia, fica claro que Comunicação e Expressão e Estudos Sociais ganharam mais atenção na formação de professores por este Projeto porque, conforme apresentado por Lima (2019, p. 90), a essas duas disciplinas foram dedicados mais módulos e número de horas.

Após a revisão e reformulação do Logos I que lhe alterou as disciplinas e respectivas cargas horárias “o DSU/MEC lançou o Projeto Logos II, em três fases, habilitando professoras e professores em nível de $2^{\circ}$ grau, utilizando as mesmas técnicas e metodologias do Logos I” (LIMA, 2019, p. 92).

Em sua $1^{\text {a }}$ fase, ele atingiu as seguintes unidades federadas: Piauí, Rio Grande do Norte, Paraná e o Território de Rondônia. Na sua $2^{a}$ fase ele cobriu as seguintes áreas: estados da Paraíba, Pernambuco, Amazonas, Roraima, Ceará, Maranhão, Sergipe, Minas Gerais, Santa Catarina e Acre. Em 1980, foi implantado nos estados do Pará, Bahia, Rio de Janeiro, Mato Grosso e Mato Grosso do Sul (VALE, 1981, p. 27, apud LIMA, 2019, p. 92).

O Projeto Logos II foi desenvolvido em convênio com as Secretarias de Educação e Cultura de 19 unidades federadas (STAHL, 1986, p. 22) desde a década de 1970 até a de 1990, com mais intensidade na de 1980.

O Logos II possuía uma equipe de Coordenação Central (situada em Brasília), que recebia acessória (sic) do Centro de Ensino Técnico de Brasília (CETEB), responsável pelo controle e avaliação do Projeto, e Grupos de Coordenação Regional localizado nos estados que aderiram ao Projeto - denominados de Gerências Regionais -, esses eram responsáveis pela criação de Núcleos Pedagógicos (NP) constituído por um gerente, um subgerente, um coordenador de supervisão, de orientação e o pessoal administrativo (CEBTEB, 1984). As gerências regionais, eram incumbidas do treinamento dos Orientadores-Supervisores Docentes (OSD) (LIMA, 2019, p. 93).

O material era constituído de módulos como já dito, livros de 20 a 40 páginas cada um a ser estudado em casa, "à distância” como narrou uma entrevistada, portanto, a formação dava-se enquanto o(a) professor(a) continuava com o seu trabalho de docente.

As avaliações do estudo dos módulos eram presenciais, o que exigia deslocação em condições muito precárias — "Quantas e quantas vezes nós ficava encalhados na estrada, por causa da chuva. Estourava pneu” (PCM2). As dificuldades surgiam e tinham que ser resolvidas para darem conta dos compromissos. A PCM1 relata que: "Uma vez o meu irmão tava me levando e ela indo atrás de caminhão. Nós tava indo de caminhão, quando foi lá numa altura 
furou o pneu. Descemos nós duas e ó na estrada, correndo, nós tinha prova, às $8 \mathrm{~h}$ nós tinha que tá sentado dentro da sala”.

Após dois anos de formação pelo Logos II, a distância a percorrer para fazerem as avaliações diminuiu: "foram 2 anos, depois fizeram um grupo aqui na Comunidade. Nós ia a pé até a Comunidade. $10 \mathrm{~km}$ daqui lá. Eu tava grávida da minha filha. Ia a pé, meu Deus!” (PCM2). A família ajudava para que não desistissem: "Eu, grávida primeira filha. Nasceu minha menina. Eu disse: quer saber de uma coisa, vou parar de fazer o magistério. Não guento (sic) mais. Minha avó e meu pai disse 'você não pode parar, você tem que continuar'. [...] com 10 dias de dieta, eu fui lá e fiz 12 provas. Porque o Logos vinha separado” (PCM1).

Para a Região dos Campos Gerais, pesquisa realizada por Vale e Góes (2013, p. 1) dá conta de que:

Os pesquisadores puderam imaginar os sacrifícios enfrentados pelas professoras primárias. E elas, sempre em serviço, ativas na sala de aula durante o dia. Do distrito de Itapará ao centro de Irati, por exemplo, percorriam semanalmente os $55 \mathrm{~km}$ de uma estrada 'natural' acidentada. Nos depoimentos, revelaram que as muitas que persistiram ficaram plenamente realizadas.

Mais tarde, PCM1 matriculou-se no curso de Pedagogia, na PUC Paraná, cursou um ano, "muita dificuldade" a impediu de prosseguir. PCM2 formou-se pedagoga, incentivada pela filha que também se fez pedagoga: "Do Logos nós foi para Pedagogia. Era difícil. Quantas e quantas vezes nós ficava encalhados na estrada, por causa da chuva. Estourava pneu” (PCM2).

A formação do professor em serviço foi sempre e ainda é um desafio a ser pensado. O Projeto Logos II foi um programa de formação de professores entre outros, no Paraná foi implementado concomitantemente com o Projeto HAPRONT (Habilitação de Professor Não Titulado), aprovado no final da década de 1970. O propósito era aprimorar a qualidade dos profissionais.

$\mathrm{Na}$ década de 1980, os programas de formação dos professores "leigos" foram submetidos ao crivo do exame crítico. Stahl (1986, p. 23) apontava, entre outras características que:

não reconhecem a experiência de formação do professor, nem a realidade em que trabalha; apresentam o magistério como profissão que exige alta dose de sacrífico e abnegação, devendo a questão salarial ficar em plano secundário; baseiam-se em uma concepção de 
educação conservadora, em que predomina a transmissão de informações, não dando margem a questionamentos e reforçando a atitude passiva, ao mesmo tempo que apresentam uma idealização do professor e seu papel; justificando-se em termos de resultados mensuráveis de valor econômico [...].

A abnegação, sacrifício, conforme destacado por PCM1, com cessão de espaço da própria casa para ser sala de aula durante de cinco anos. Nessas circunstâncias, era exigido das professoras todo tipo de trabalho. “[...] era professora, secretária, merendeira, era 'tudo' [...] Começamos com meio salário mínimo. Depois de uns 15 anos de serviço nós passamos para 1 salário e meio [...]. Nós ficamos faceiras. Eu fiquei faceira porque achei que tava ganhando muito bem. Eu trabalhei muito".

Tesser (1993) analisou duas áreas de conhecimento do referido Projeto Logos II, Sociologia Educacional e História da Educação, e concluiu que “O caráter meramente memorativo e descompromissado dos módulos não permite descobrir neles um serviço à educação e sim um atavismo intelectual, útil apenas para o ritual de uma falsa legitimação profissional” (TESSER, 1993, p. 203).

Stahl (1986, p. 23) defendia na década de 1980 para a formação de professores(as):

Deve-se considerar que o professorado leigo é composto de profissionais, muitos com vários anos de magistério, e explorar sua vivência, tanto do ponto de vista de valorização de sua experiência quanto do da realidade em que atuam, promovendo a participação dos professores nas tomadas de decisão que vão afetar suas vidas e seu trabalho $[\ldots]$.

Teses tão próximas aos princípios que o movimento da Educação do Campo propõe e que muitas vezes se faziam realidade no dia a dia das professoras, dado o trabalho que assumiam na comunidade.

Perto das comunidades e longe das Secretarias de Educação, "Não tinha apoio. Eles não davam assistência, nós se virava" (PCM1), mas, "Final do ano vinham fazer prova" (PCM2), "só no final do ano [...]. Eu ficava nervosa, minha perna tremia. Eu tremia que nem vara verde. Eles chegavam. Tremia eu que era professora e tremiam os aluno" (PCM1).

Em síntese, a duas professoras mencionadas nesta seção são representativas do que as demais vivenciaram como experiência pedagógica e formação inicial. Ou 
seja, do trabalho fizeram o lugar de aprendizagem, de formação inicial e continuada, antes que os cursos de magistério, presencial ou a distância, fossem ofertados. A realidade das professoras idosas do campo é de envolvimento e luta diária para possibilitar o ensino às crianças do campo.

Na próxima seção serão expostos alguns aspectos da organização curricular, do planejamento do ensino e do trabalho nas escolas.

\section{0 trabalho nas escolas rurais: planejamento e organização curricular}

As professoras realizavam todo tipo de trabalho na escola, desde a limpeza, a alimentação, a organização pedagógica, a divisão de materiais pedagógicos. Era uma vida na escola, com extensão do trabalho na família e, às vezes, do trabalho na roça. Elas construíam as condições objetivas para a existência da escola e do processo educativo. Como afirma PCM1 "ninguém ficava sem aprender".

O trabalho de professoras "leigas" em escolas multisseriadas configurou a realidade da escola rural no Brasil, principalmente até a década de 1980, quando são intensificadas as políticas de fechamento destas escolas e de consolidação de escolas rurais seriadas. A docência destas professoras representou a luta pelo direito à educação e transformação das condições objetivas de vida e de trabalho no campo. Assumiu às vezes a condição de resistência, ao contestar a cultura e o modo de produção capitalista, como também de submissão imposta pelos múltiplos determinantes "externos e internos"3 que se expressam na prática pedagógica.

O perverso desamparo ao território rural e a educação de suas comunidades são revelados nas narrativas das professoras idosas, que, apesar das dificuldades, resistiram e, com o comprometimento de seu trabalho, buscaram alternativas para a

\footnotetext{
${ }^{3}$ Compreende-se por determinantes internos a lógica escolar como rotinas, horários, regras disciplinares, relações hierárquicas entre direção, coordenação pedagógica, professores, alunos, funcionários e comunidades, dentre outras. Por determinantes externos entende-se o conjunto de diretrizes curriculares, o próprio currículo escolar, a legislação educacional, as resoluções, portarias e normativas nacionais, estaduais e municipais, os materiais didático-pedagógicos fornecidos pelo Ministério da Educação, produzidos por diversas editoras, e aqueles materiais que adentram na escola oriundos de cooperativas, os processos avaliativos externos, criados nos municípios, estados e pelo governo federal (SOUZA, 2016b, p. 42, 43)
} 
concretização da escola pública em seus territórios. Os relatos expressam as enormes dificuldades enfrentadas para realizar suas aulas em escolas improvisadas, sem orientação, sem materiais, em turmas multisseriadas e com grande número de alunos. Como relata PCM2, "a turma tinha em média 48 alunos, naquele tempo. Desmancharam a escola e a gente dava aula no paiol, era chão de terra”.

No começo, pra mim foi difícil, porque só recebi o livro de chamada e nada mais sabe. Então não tinha nenhum Programa, eu não tinha nada mais sabe. Eu me baseava até me baseei muito nas primas minhas que estudavam na cidade [...] os cadernos delas sabe, toda a matéria que elas tinham lá de $1^{\mathrm{a}}, 2^{\mathrm{a}}, 3^{\mathrm{a}}, 4^{\mathrm{a}}$. Era difícil porque era bastante criança, eu lecionei para 60 alunos, era multisseriada. Olha eu me bati! Muito! Muito! Muito! (PPS1).

Comecei na escola multisseriada, tinha 46 alunos sabe, ninguém sabia nada. A Dona Dalva veio me ajudar sabe, me ajudar no começo porque até nem experiência eu tinha né, então ela veio tinha que fazer merenda para todos os alunos, varrer e limpar o salão e buscar água no rio, no poço próximo que tinha ali pra baixo, pra poder fazer merenda (PPS2).

As narrativas indicam o expressivo número de alunos nas salas de aula, o que revela a presença do trabalhador do campo em seu território, condição que foi se modificando devido ao investimento em políticas urbano-industriais, que reduziram oportunidades de trabalho no campo, reforçaram a concentração da propriedade e constituíram fundamentos para as políticas de fechamento de escolas.

As professoras reconhecem a contribuição da escola multisseriada para a aprendizagem das crianças de idades diferentes, assim como a de ela existir na comunidade onde a criança e o professor moram devido à identidade que eles constroem com o campo. Esta compreensão coincide com estudos sobre aprendizagens e currículo em classes multisseriadas, como também com as lutas para o não fechamento de escolas isoladas desencadeadas pelo movimento da Educação do Campo.

$\mathrm{Na}$ classe multisseriada existem dois lados. Um lado, porque um vai aprendendo com o outro né, uma criança aprende com a outra e se ajudam. E por outro lado, dependendo da quantidade de alunos atrapalha, seria... tudo questão de... quantidade de aluno. Trabalhar com uns vinte alunos ali dá pra trabalhar tranquilo, mais do que isso atrapalha. Tem que ter um tempinho individual pra cada aluno. Ver o que eles vão fazer, o que eles conseguem, o que não conseguem, e assim vai. E a partir do momento que eles já têm um início, eles vão se apoiando também nos outros (PTS1). 
As professoras construíam a prática pedagógica em meio às múltiplas funções que exerciam para além da docência.

Nós fazíamos a merenda, lavava a escola, varia o pátio, tudo era nós com os alunos, nós e eles traziam né, uma polenta, alguma coisa. Depois que começou uma merendinha aqui. Mas era ruim, vinham aqueles de 5 quilos, já temperado, aquelas sopa. Era pôr a água e aquilo. Uma sopa preta, que dava dor de barriga nas crianças e coisas doces. (PTS2)

Eu, morava a quase $4 \mathrm{~km}$ da escola, levava uma panelinha de casa. Na escola não tinha fogão, não tinha cozinheira, nada. Levava uma panelinha de merenda. Era servido pouquinho, numa canequinha. Cada criança levava a sua canequinha. $\mathrm{O}$ que eu achava mais difícil era levar a panelinha de merenda, longe. A gente levava quente... quantas vezes a gente tropeçava e derramava. Além de ser pouco, né... (PCM2).

Não bastava ter 4 turmas na sala, ainda mandavam os pequenininhos para cuidar. [...] Tinha mês que eu tinha 8 ou 10 pequenos com cinco anos dentro da sala. Se eles não trouxessem os irmãos pequenos, eles não podiam vim para escola. Daí quando dava calor, eu deixava eles num cantinho lá, quando ia ver, tava tudo dormindo. A gente sofreu demais. Tem dias que eu fico pensando, não sei como ainda eu consegui me aposentar. (PCM1).

Na mesma sala, era uma sala só. Uma sala só. Era o 10, 20, $3^{\circ}$ e 40 ano. Ainda levava meus filhos junto, levava um cobertor colocava no chão. Eles tinham que ficar junto comigo, não tinha alternativa. O pai ia pra roça, mas antes os alunos eram bem melhor, eles obedeciam a gente, nossa a gente pra eles era uma segunda mãe lá (PPS2).

Então eu procurava trabalhar individual com ele pra ver o que estava acontecendo. Eu fazia prova, porque tinha que fazer prova. Mas eu não avaliava o aluno pela prova. É pelo dia a dia dele, o que ele conseguiu fazer, o dever de casa, então era aquilo e eu ficava feliz da vida. Então é nessas coisinhas que eles não tão levando em consideração ter uma nota nisso... Então, eles faziam mais livres, não era uma prova (PTS1).

Conforme afirma Therrien (1993) as professoras das escolas rurais são sujeitos históricos, com determinados saberes e práticas sociais, incorporados pelas experiências em seu meio, que transcendem e integram o saber escolar. A professora rural é gerada pela estrutura social de seu contexto de vida, e nessa mesma estrutura constrói sua identidade pedagógica (THERRIEN, 1993, p. 44).

As determinações políticas, sociais e educacionais presentes na realidade das escolas e salas de aulas influenciaram a construção da identidade das professoras rurais. Determinantes internos e externos tais como: o programa de conteúdos definido e avaliado pelas Secretarias de Educação, a carência de materiais pedagógicos, as multitarefas desempenhadas, marcaram a conformação e em outros momentos a transformação de sua prática em relação às políticas vigentes, como também, em relação às condições de trabalho na escola. 
No final do ano nós tínhamos que fazer o relato de todos os alunos, ver quem passava, quem não passou e passar tudo para a secretaria. Isso aí foi tudo coisa que eu fiz. Eu sempre digo para as pessoas, gente eu tenho um conhecimento de professora que as professoras que tão hoje, se elas perguntarem para mim, elas se assustam. Nós fazia tudo (PCM1).

Tinha a cartilha né, tinha os manuais do professor que eram desse tamanho sabe, daí a gente ia lá o dia inteiro e ficava discutindo o conteúdo né, fazer planejamento, depois a Secretaria mandava pra gente. Eles vinham e faziam a prova, a gente só ensinava, Daí vinha a Secretária, mandava alguém lá e daí eles faziam a prova, às vezes a gente nem via a prova sabe, nem sabia o que estava ali. Então a gente tinha que morrer de ensinar (PPS2).

Não tinha apoio. Eles não davam assistência. Final de ano eles vinham fazer prova. Na época não era dividido o conteúdo. Eles viam tudo que aprenderam no ano para aplicar uma prova só. $\mathrm{O}$ inspetor aplicava a prova. Imagine para a criança (PCM2).

A gente tinha muito pouco material. Depois de muito tempo eles mandaram o conteúdo para nós. Mas, mandavam o conteúdo inteiro, fechado [...] Daí, a gente ia rabiscando ali e tirava todo conteúdo. Eu ficava com o meu conteúdo, ela com o dela... Mas, ele vinha inteiro, do jeito que eles faziam para nós. Isso era como um teste [...] os materiais eram todos divididos. Por exemplo, lápis, eu cortava o lápis no meio. Metade para cada aluno. Borracha fazia 4 pedaços. 0 caderno, brochura, tirava 8 a 10 folhas para fulano, para ciclano e assim fazia. (PCM1).

As relações de trabalho materializadas nas experiências das professoras das escolas do meio rural revelam a luta pela sobrevivência, como também o compromisso com a educação e desenvolvimento de suas comunidades, estabelecendo vínculos de solidariedade e de formação humana. A forte relação das professoras com a natureza de seus territórios resulta de sua práxis empírica, permeada por valores e atitudes, que se efetivam em acertos e erros e, com isso, promovem a construção de saberes sociais e de sua identidade pedagógica, consonantes com os interesses da educação da classe camponesa.

O aprendizado do dia a dia... Esse aluno conseguiu, aquele aluno não conseguiu, então vamos trabalhar assim... Então é isso que eu sinto falta. Porque a gente sabe que tem muita criança com dificuldade, precisa de um acompanhamento mais de perto e ver a realidade de cada criança. Entrar no mundo da criança de uma maneira verdadeira, jamais mentir pra uma criança. O conteúdo sobre o campo, a gente forçava um pouquinho porque a gente é do campo, as crianças são do campo, trazem um pouquinho mais a realidade de cada um, né. Só que, nos mesmos livros que a gente usava assim, não tinha muito com o campo não. Alguma coisa sim né, mas não era muito não (PTS1).

Eu também lia, eu gostava. Aquelas histórias infantil, não tinha tv, ai eu ficava lá com os livros. Eu gostava muito de teatro, daí eu gostava de dar teatro pras criança. Eu fazia festa aqui, eles eram tudo personagem, mas enchia de gente. Eu sempre gostei disso... Eu fazia com material reciclado. E eu gostava de passar uma mensagem pra eles né. Nossa como eu gostava dessa parte (PTS2). 
A intencionalidade da prática pedagógica reflete a consciência que as professoras têm do objetivo do seu próprio trabalho, que dialoga com as necessidades de seus alunos, acompanha suas dificuldades e interesses e promove diversidades de aprendizagens. Embora sem formação específica para o trabalho com os conteúdos do campo, o conjunto de conhecimentos, valores e atitudes produzidos em suas práticas sociais constitui seus saberes como instrumentos teóricos da prática pedagógica.

As narrativas das professoras idosas do campo revelam que elas se consideram realizadas pela importante contribuição que deram à educação de suas comunidades, que retribuem com reconhecimento e valorização. As professoras cônscias de sua responsabilidade social se vinculam e se comprometem com o projeto emancipador da realidade camponesa e acreditam que seu trabalho significa transformação na vida de seus alunos.

Embora houvesse o controle por parte das secretarias municipais de educação, que realizavam as avaliações com as crianças e com as professoras, constata-se que a criação pedagógica ficava por conta delas. Da infraestrutura à formação pedagógica, as professoras foram as protagonistas principais da existência da escola rural. As comunidades, com suas organizações políticas incipientes, responsabilizavam-se pela manutenção da escola e pelo reconhecimento da importância do trabalho das professoras.

As professoras, por sua vez, conheciam todos os alunos, suas famílias, necessidades, fato que tornava o processo formativo vivo, carregado das relações pedagógicas que traziam o mundo da vida para a escola.

Um ponto destacado por uma das 7 professoras diz respeito às festividades na escola e à união das comunidades.

Com brilho no olhar e cheia de orgulho, a professora relata os bailes, os fandangos. Aprendiam o fandango com as pessoas do lugar. "Ah, tempo bom, cada fandangão que nos fazia. Na escola, eu corri atrás da música e tudo. E, nós fizemos o fandango, roupa, tamanco..." (PCM1). Como relata PCM2, "Nós fazíamos jantar típico, de comidas da região. Agora acabou tudo. As famílias participavam de tudo”. 
Além dos aspectos culturais, as professoras relatam a relação com os familiares. Elas lembram do auxílio que os familiares davam em relação aos conteúdos, aproximando a Matemática com o trabalho na lavoura. A aprendizagem significativa construída com base na experiência vivida pela professora e pelos familiares no cultivo da terra. Para PCM2, "Fazia a aproximação com o trabalho na terra, quando usava muito a mediação de braça, palmo, meia, litro tudo. Os pais trabalhavam com roçado, às vezes eles levavam para escola para as crianças aprenderem medidas".

Os pais ajudavam a ensinar porque você veja, nós da lavoura, nós não trabalhamos com, na época que nós fomos professoras, a nossa região trabalhava só no arado, porque não tinha trator ainda. Era arado de animal. Daí, o que era feito? Era feita a medição na braça, não era no metro. Na realidade a braça são $2 \mathrm{~m} 20$. Na eram 12 palmos (PCM1).

As professoras falam de um tempo, anos de 1980 e 1990, quando não se conhecia a Educação do Campo como hoje. Entretanto, as narrativas dão conta de uma escola que vivia o ritmo das comunidades. A sociabilidade, os cuidados na organização do espaço escolar, o planejamento dos conteúdos, os "jeitos" de tratar os conteúdos, tudo era movimentado pelas professoras. Embora elas estivessem sob o "olhar" das secretarias locais, entre receios e iniciativas, pode-se afirmar que as escolas existiram pela luta delas na e com as comunidades.

Quando as professoras atingiram o tempo da aposentadoria, relatam que sentiram felicidade e tristeza. Há relatos de professoras que se viram no ponto do ônibus, esperando o transporte para a escola. Outras que continuaram indo para as escolas, até conseguirem atingir o que denominam de "desapego" de todo o trabalho na escola. Há professoras que continuaram com atividades pedagógicas familiares, cuidando de crianças de outras famílias, enquanto pais e mães trabalhavam.

Enfim, há as professoras que continuam trabalhando nas atividades da agricultura familiar, demonstrando realização com o trabalho com a terra e encerramento de um ciclo de atividades na esfera escolar.

Ouvir as narrativas das professoras, na perspectiva de Souza (2014), nos faz repensar a relação entre escola, campo, políticas públicas e comunidades. Narram 
experiências da trajetória profissional, com suas lutas cotidianas. As professoras não relatam vivência de processos formativos críticos em relação ao campo, à contradição capital e trabalho e nem às relações entre campo e cidade, porém demonstram a valorização do trabalho no campo e a importância da comunidade para a existência da escola pública.

\section{Considerações finais}

As escolas rurais sob o olhar das professoras idosas do campo estavam imersas em relações pedagógicas pautadas pelo trabalho e condições de vida das famílias. Relatam a preocupação com a aprendizagem das crianças. É comum elas dizerem "ninguém ficava sem aprender", mesmo que tivesse que dividir lápis, folha de caderno. O fundamental era que todas as crianças tivessem a mesma condição de aprendizagem e de alimentação. Quanto aos conteúdos, havia a determinação das secretarias municipais e a avaliação realizada ao final do ano, entretanto, é comum a afirmação das professoras de que o planejamento, o dia a dia da sala de aula era decisão delas, dependia da experiência delas, das trocas realizadas com outras colegas de trabalho.

Consideradas professoras "leigas", elas afirmam que o papel das professoras "antigas" da escola era central, pois elas davam as "dicas" para o trabalho pedagógico. Estamos diante de professoras que narram uma história de formação pautada pela experiência na prática. Eram colocadas em turmas com 40 ou mais alunos, em classes multisseriadas, e tinham que dar conta. Portanto, como elas afirmam, "se viravam" no processo pedagógico, faziam as crianças estudarem muito, para além dos conteúdos indicados pelas secretarias municipais de educação.

Nas narrativas, as professoras se organizavam para dar conta de muitas jornadas de trabalho, marcadas pelos trabalhos em casa, cuidados com os filhos, trabalho na roça, trabalho na escola, tanto o pedagógico como os serviços gerais de limpeza e merenda.

As professoras idosas têm a realização no olhar, fazem os relatos com muita empolgação e com o sentimento de que fariam tudo novamente. Além disso, 
relatam o sentimento de pertença à escola e a dificuldade com o "desapego" quando atingiram o momento da aposentadoria.

\section{Referências}

ALENTEJANO, P. Modernização da Agricultura In: CALDART, R. S. et al. (org.). Dicionário da Educação do Campo. Rio de Janeiro; São Paulo: Expressão popular, 2012.

BASTOS, A. S.; SOUZA, E. C. História de vida-formação de uma professora idosa aposentada. Revista Brasileira de Educação de Jovens e Adultos, v. 5, n. 10, 2017.

BRASIL. Decreto-Lei $\mathrm{n}^{\circ}$ 8.529, de 2 de janeiro de 1946. Lei Orgânica do Ensino Primário. Rio de Janeiro, 2 de janeiro de 1946. Disponível em: https://www2.camara.leg.br/legin/fed/declei/1940-1949/decreto-lei-8529-2-janeiro-1946458442-publicacaooriginal-1-pe.html. Acesso em: 13 ago. 2020.

BRASIL. Lei no 4.024, de 20 de dezembro de 1961. Fixa as diretrizes e bases da Educação Nacional. Brasília, 1961. Disponível em: http://www.planalto.gov.br/ccivil_03/leis/L4024.htm. Acesso em: 20 fev. 2020.

BRASIL. Lei $n^{\circ}$ 5.692, de 11 de agosto de 1971. Fixa diretrizes e bases para o ensino de $1^{\circ}$ e $2^{\circ}$ graus. Brasília, 1971. Disponível em: http://www.planalto.gov.br/ccivil_03/leis/L4024.htm. Acesso em: 20 fev. 2020.

BRASIL, Lei no 9.394, de 20 de dezembro de 1996. Dispõe sobre as diretrizes e bases da Educação Nacional. Brasilia, 1996. Disponível em: http://www.planalto.gov.br/ccivil_03/leis/19394.htm Acesso em: 20 fev. 2020.

BRASIL. Lei $\mathrm{n}^{\mathrm{o}}$ 10.172, de 9 de janeiro de 2001. Aprova o Plano Nacional de Educação e dá outras providências. Brasília, 2001. Disponível em: http://portal.mec.gov.br/arquivos/pdf/L10172.pdf Acesso em: 2 fev. 2020.

BRASIL. Ministério da Educação. Resolução CNE/CEB n ${ }^{\circ}$ 1, de 3 de abril de 2002. Institui Diretrizes Operacionais para a Educação Básica das Escolas do Campo. Diário Oficial da União, Poder Legislativo, Brasília, DF, 9 abr. 2002.

BRASIL. Ministério da Educação. Resolução CNE/CEB no 2, de 28 de abril de 2008. Estabelece diretrizes complementares, normas e princípios para o desenvolvimento de políticas públicas de atendimento da Educação Básica do Campo. Diário Oficial da União, 29 abr. 2008. Seção 1, p. 25-26.

BRASIL. Decreto $\mathrm{n}^{\circ}$ 7.352, de 4 de novembro de 2010. Dispõe sobre a política de Educação do Campo e o Programa Nacional de Educação na Reforma Agrária PRONERA. Diário Oficial da União, Poder Legislativo, Brasília, DF, 5 nov. 2010.

BRASIL. Lei no 13.005, de 25 de junho de 2014. Aprova o Plano Nacional de Educação e dá outras providências. Brasília, 2014. Disponível em: http://pne.mec.gov.br. Acesso em: 10 fev. 2020. 
CABRAL, S. O. L. et al. Condições de ambiente e saúde em idosos residentes nas zonas rural e urbana em um município da Região Nordeste. Geriatria \& Gerontologia, v. 4, n. 2, p. $76-84,2010$.

CALAZANS, M. J. C. Para compreender a educação do estado no meio rural (traços de uma trajetória). In: THERRIEN, J.; DAMASCENO, M. N. (Orgs.). Educaşão e escola no campo. Campinas: Papirus, 1993.

COELHO, P. J. S. Trajetórias e narrativas de professoras de Educaşão Infantil de meio rural de Itaberaba-BA: formação e práticas educativas. 185f. Dissertação (Mestrado em Educação) - Universidade do Estado da Bahia, Salvador, 2010. Disponível em: http://www.cdi.uneb.br/site/wp-content/uploads/2016/01/patricia_julia_souza_coelho.pdf. Acesso: 11 set. 2019.

GUSMÃO, N. M. M.; ALCÂNTARA, A. O. Velhice, mundo rural e sociedades modernas: tensos itinerários. Ruris (Revista do Centro de Estudos Rurais), Campinas, v. 2, n. 1, p. 154-180, mar. 2008. Disponível em http://www.ifch.unicamp.br/ceres/2008-neusa_gusmao.pdf. Acesso em: 23 set. 2019.

GRITTI, S. Educação rural e capitalismo. Passo Fundo: Editora da UPF, 2003.

INSTITUTO NACIONAL DE ESTUDOS E PESQUISAS EDUCACIONAIS ANÍSIO TEIXEIRA (INEP). Notas Estatísticas. Censo Escolar 2018. Disponível em: http://download.inep.gov.br/educacao_basica/censo_escolar/notas_estatisticas/2018/not as_estatisticas_censo_escolar_2018.pdf. Acesso em: 19 abr. 2020.

INSTITUTO NACIONAL DE ESTUDOS E PESQUISAS EDUCACIONAIS ANÍSIO TEIXEIRA (INEP). A Educação Rural no Brasil. 2006. Disponível em: http://portal.inep.gov.br/informacao-da-publicacao/-/asset_publisher/6JYIsGMAM kW1/document/id/488904. Acesso em 19 abr. 2020.

LIMA, R. S. Se en nascesse de novo quarenta e duas vezes en seria professor nas quarenta e duas vidas: o fazer-se professor e professora rural em fins do século XX, em Ariquemes, Rondônia. Dissertação (Mestrado Acadêmico em Educação) - Fundação Universidade Federal de Rondônia, Porto Velho, 2019.

QUEIROZ, M. I. P. Relatos orais: do indizível ao dizível. In: VON SIMSON, O. R. M. (Org.). Experimentos com histórias de vida (Itália-Brasil). São Paulo: Vértice, 1988.

RIBEIRO, M. Educação Rural. In: CALDART, R. S. et al. (org.). Dicionário da Educação do Campo. Rio de Janeiro; São Paulo: Expressão popular, 2012.

STAHL, M. M. Reflexões sobre a formação do professor leigo. Em Aberto, Brasília, ano 5, n. 32, out./dez. 1986.

SOUZA, E. C. Diálogos cruzados sobre pesquisa (auto)biográfica: análise compreensivainterpretativa e política de sentido. Educação, Santa Maria, v. 39, n. 1, p. 39-50, jan./abr. 2014. Disponível em: https://periodicos.ufsm.br/reveducacao/article/view/11344. Acesso em: 13 ago. 2020.

SOUZA, M. A. A Educação do Campo no Brasil. In: SOUZA, E. C.; CHAVES, V. L. J. (Orgs.). Documentação, Memória e História da Educação no Brasil: diálogos sobre políticas de educação e diversidade. Tubarão: Copiart, 2016a. v. 1, p. 133-158. 
SOUZA. M. A. Sobre o Conceito de Prática Pedagógica. In: SILVA, M. C. B. (Org.). Práticas pedagógicas e elementos articuladores. Curitiba: Universidade Tuiuti do Paraná, 2016b.

TESSER, O. O conteúdo da formação pedagógica do Logos II: a sociologia educacional e a história da educação. In: THERRIEN, J.; DAMASCENO, M. N. (Orgs.). Educação e escola no campo. Campinas: Papirus, 1993.

THERRIEN, J. A professora rural: o saber de sua prática social na esfera da construção social da escola no campo. In: THERRIEN, J.; DAMASCENO, M. N. (Orgs.). Educação e escola no campo. Campinas: Papirus, 1993.

VALE, A. M.; GÓES, R. R. A Experiência do Projeto Logos II. Estado, políticas públicas e estratégias para a capacitação de professores primários: no Paraná (1976-1988), entrevistas e reflexões sobre pobreza do trabalhador e professores não titulados. EFDeportes.com, Revista Digital, Buenos Aires, año 18, n. 185, oct. 2013. Disponível em: https://www.efdeportes.com/efd185/a-experiencia-do-projeto-logos-ii.htm. Acesso em: 30 abr. 2020.

RECEBIDO: 07/05/2020

APROVADO: $14 / 08 / 2020$

RECEIVED: 05/07/2020

APPROVED: 08/14/2020

RECIBIDO: 07/05/2020

APROBADO: $14 / 08 / 2020$ 